\title{
Self-Powered, Broad Band, and Ultrafast InGaN-Based Photodetector
}

\author{
Arun Malla Chowdhury, ${ }^{\dagger}$ Greeshma Chandan, $^{\dagger}$ Rohit Pant, $^{\dagger}{ }^{\dagger}$ Basanta Roul, ${ }^{\dagger,}$ \\ Deependra Kumar Singh, ${ }^{\dagger}$ K. K. Nanda, ${ }^{* \dagger}{ }^{\dagger}$ and S. B. Krupanidhi ${ }^{*}{ }^{\dagger}$ \\ ${ }^{\dagger}$ Materials Research Centre, Indian Institute of Science, Bangalore 560012, India \\ ${ }^{\ddagger}$ Central Research Laboratory, Bharat Electronics, Bangalore 560013, India
}

\section{Supporting Information}

ABSTRACT: A self-powered, broad band and ultrafast photodetector based on $\mathrm{n}^{+}-\mathrm{InGaN} / \mathrm{AlN} / \mathrm{n}-\mathrm{Si}(111)$ heterostructure is demonstrated. Si-doped $\left(\mathrm{n}^{+}\right.$type) InGaN epilayer was grown by plasma-assisted molecular beam epitaxy on a $100 \mathrm{~nm}$ thick AlN template on an n-type $\mathrm{Si}(111)$ substrate. The $\mathrm{n}^{+}-\mathrm{InGaN} / \mathrm{AlN} / \mathrm{n}-\mathrm{Si}(111)$ devices exhibit excellent selfpowered photoresponse under UV-visible (300-800 nm) light illumination. The maximum response of this self-powered photodetector is observed at $580 \mathrm{~nm}$ for low-intensity irradiance $\left(0.1 \mathrm{~mW} / \mathrm{cm}^{2}\right)$, owing to the deep donor states present near the InGaN/AlN interface. It shows a responsivity

of $9.64 \mathrm{~A} / \mathrm{W}$ with rise and fall times of 19.9 and $21.4 \mu \mathrm{s}$, respectively. A relation between the open circuit voltage and the responsivity has been realized. KEYWORDS: molecular beam epitaxy (MBE), indium gallium nitride, $S-I-S$ heterojunction, self-powered detectors, broad band detectors

\section{INTRODUCTION}

The photodetectors are of great importance due to their various applications from everyday consumer electronics (compact disk players, smoke detectors, remote control, etc.) to more elegant applications, such as environmental monitoring, space research, and optical communication. ${ }^{1,2}$ Photodetectors work on various mechanisms, such as photoelectrochemistry, ${ }^{3}$ photoconduction, or photodiode action. ${ }^{4}$ Most of the photodetectors require an applied bias for appreciable detectivity, which needs a constant electrical power source. As a result, overall circuitry becomes heavy and unprofitable in the current energy framework. A selfpowered photodetector can operate at zero bias without any external power source. There are many reports of photodetectors that are based on the photovoltaic effect. ${ }^{5-14}$ The selfpowered photodetectors, such as $\mathrm{p}-\mathrm{n}$ junction, heterojunction, Schottky junctions, and organic/inorganic hybrid junctions, can immediately separate the electron-hole pairs due to the built-in electric field, which shows faster photoresponse and higher responsivity at zero bias ${ }^{15-19}$ and has drawn much attention of scientists and technologists.

Most of the photodetectors comprise of inorganic semiconductors (InGaAs, $\mathrm{ZnO}$, etc.), ${ }^{20-22}$ which show attractive properties, such as high carrier mobility and high-absorption coefficients, but suffer from drawbacks, such as high toxicity, a narrow detection range, large exciton binding energy, large intensity irradiance, and low responsivity. III-nitride materials (AlN, GaN, and InN), on the other hand, can be used as a
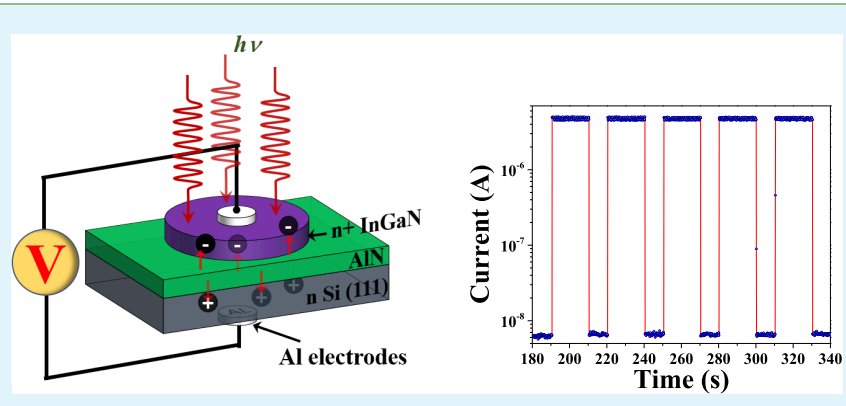

replacement of toxic elements as well as their lower values of exciton binding energies, as compared with other materials, facilitate easier separation of electrons and holes. Moreover, the tunability of III-nitride materials from the ultraviolet to infrared region makes them useful over other materials for high-speed optoelectronic applications.

Among III-nitrides, InGaN alloys have attracted much attention for wider band gap photodetectors as well as in photovoltaic applications because of their direct and large band gap, which can be tuned from 0.7 to $3.4 \mathrm{eV}$, superior electronic properties, chemical inertness, mechanical stability, and capability of forming heterostructures. ${ }^{23,24}$ The tuneable band gap makes InGaN-based devices useful for photovoltaic applications. $^{24-27}$ InGaN-based broad band photodetectors have great significance in several high-tech applications, including imaging, sensing, optical communications, energy harvesting, and biological research. ${ }^{28-33}$ The key point of a broad band photodetector is that it occupies multiple passbands, therefore allowing much higher throughput over a single medium.

There are few reports on InGaN-based self-powered and broad band photodetectors, ${ }^{34,35}$ but these are accompanied by several limitations, such as lower responsivities, high rise and fall

Received: December 27, 2018

Accepted: February 21, 2019

Published: February 21, 2019 
times, a narrow detection range (UV), etc. InGaN epilayers have been grown on $\mathrm{AlN}, \mathrm{GaN}$, and $\mathrm{InN}$ buffer layers using $\mathrm{Si}$ and $\mathrm{Al}_{2} \mathrm{O}_{3}$ substrates by different groups. ${ }^{24,36-38}$ Here, $\mathrm{n}^{+}$-InGaN has been grown on $\mathrm{AlN} / \mathrm{Si}$ template by plasma-assisted molecular beam epitaxy (PAMBE) and the broad band photodetection of the InGaN/AlN/Si heterostructures is reported. It has been shown that $\mathrm{n}^{+}-\mathrm{InGaN} / \mathrm{AlN} / \mathrm{n}-\mathrm{Si}(111)$ can be used as a self-powered photodetector that exhibits an excellent self-powered photoresponse under UV-visible (300$800 \mathrm{~nm}$ ) light illumination. The self-powered photodetector shows a responsivity of $9.64 \mathrm{~A} / \mathrm{W}$ with rise and fall times of 19.9 and $21.4 \mu \mathrm{s}$, respectively. The maximum response of this selfpowered photodetector is observed at $580 \mathrm{~nm}$ for low-intensity irradiance and is believed to be due to the deep donor states present near the InGaN/AlN interface. A relation between the open circuit voltage and responsivity has been realized.

InGaN with the AlN buffer layer shows a Schottky behavior. This can be attributed to the fact that introduction of AlN increases the built-in potential across the junction and thereby increases the depletion region width, as a result of which the carrier lifetime increases, thus enhancing the photoresponse of the device. On the other hand, due to doping, the electric field across the junction enhances manifolds, thus increasing the drift velocities of the charge carriers, resulting in a faster photoresponse. Hence, photoelectrical properties, such as photoresponse, response and recovery time, and detectivity show huge enhancement compared to those in InGaN-based conventional detectors.

\section{EXPERIMENTAL SECTION}

The sample used for this study was grown by PAMBE. The $\mathrm{n}^{+}-\mathrm{InGaN}$ epilayer with thickness of around $110.8 \mathrm{~nm}$ was grown on a $100 \mathrm{~nm}$ thick AlN template on $\mathrm{n}-\mathrm{Si}(111)$ substrate. The In and Ga effusion cell temperatures were kept at 750 and $880{ }^{\circ} \mathrm{C}$, respectively, and the corresponding beam equivalent pressures were maintained at $1.13 \times$ $10^{-7}$ and $1.28 \times 10^{-7} \mathrm{mbar}$, respectively. Si effusion cell temperature was kept at $1250{ }^{\circ} \mathrm{C}$ for doping. During growth, $\mathrm{N}_{2}$ flow rate and plasma power were maintained at $1 \mathrm{sccm}$ and $350 \mathrm{~W}$, respectively. Thermal cleaning was done at $810{ }^{\circ} \mathrm{C}$ for $30 \mathrm{~min}$ to remove residual hydrocarbons. The substrate temperature was then reduced to 550 ${ }^{\circ} \mathrm{C}$, and growth was carried out for $3 \mathrm{~h}$ without any intermediate steps.

The structure of the epilayer was characterized by high-resolution Xray diffraction (HRXRD) to know the crystalline quality of the film. Hall studies have been performed by HMS 5000 Hall measurements system from Ecopia to know the type of InGaN layer. Thickness and roughness of the epilayer were estimated by cross-sectional field emission scanning electron microscopy (FESEM) and atomic force microscopy (AFM), respectively. A photoluminescence study was carried out to have an idea about the band gap. Structural (HRXRD, SEM, AFM) and optical characterizations show that InGaN epilayer exhibits good crystalline and optical qualities. The current-voltage (I$V)$ and photodetection characteristics of the $\mathrm{n}^{+}-\mathrm{InGaN}$ based device were studied using a Keithely-2420 source measuring unit. The temporal response was acquired using a computer-interfaced Keithely2420 source measuring unit, whereas the spectral response (300-800 $\mathrm{nm}$ ) was performed using Oriel's QEPVSI system with a Keithely-2420 source measuring unit. The Oriel's QEPVSI system consists of a $300 \mathrm{~W}$ xenon bulb with an output of $0.1 \mathrm{~mW} / \mathrm{cm}^{2}$. The aluminum circular electrodes, having diameter $400 \mu \mathrm{m}$, were deposited at the top and bottom of the device by thermal evaporation using a physical mask. Subsequent to metallization, the sample with metal electrodes was annealed in vacuum for better contact formation. The Ohmic nature of the metal contacts on $\mathrm{n}^{+}-\mathrm{InGaN}$ and $\mathrm{Si}$ was verified. The standard photolithographic process and reactive ion etching (RIE) have been used to define the InGaN area with diameter $1000 \mu \mathrm{m}$. RIE was carried out on InGaN film until the AlN layer was exposed. Moreover, the flow chart of device fabrication is depicted in Figure S1.

\section{RESULTS AND DISCUSSION}

Figure 1a represents the HRXRD $2 \theta-\omega$ scans of the InGaN epilayer grown on the AlN/Si(111) substrate. From Figure 1a, it
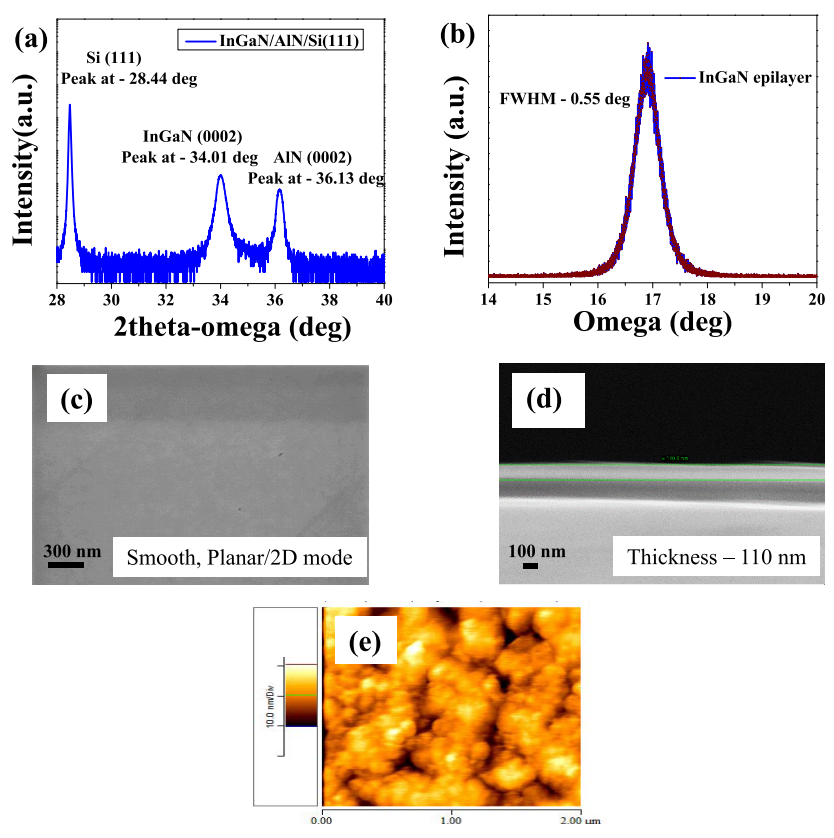

Figure 1. (a) HRXRD $2 \theta-\omega$ scans and (b) X-ray rocking curve of (0002) reflections. (c) Top surface, (d) cross-sectional FESEM, and (e) AFM image of InGaN film.

can be seen that a strong (0002) InGaN diffracted peak at $2 \theta \sim$ $34.01^{\circ}$ is present along with substrate peaks. The absence of any other peaks indicates that the as-grown sample is free from residual indium or spinoidal decomposition. The crystalline quality of InGaN epilayer was further investigated by calculating the full width half-maxima (FWHM) of the (0002) symmetry rocking curve of InGaN epilayer. The FWHM value of the epilayer was found to be $0.55^{\circ}$, as shown in Figure $1 \mathrm{~b}$. The FWHM value of the epilayer obtained is superior to that of the films grown on other substrates. ${ }^{34,39,40}$

FESEM image of $\mathrm{n}^{+}$-InGaN epilayer has been shown in Figure 1c. The thickness of InGaN layer was estimated by crosssectional FESEM (Figure 1d), and it was found to be $110.8 \mathrm{~nm}$. FESEM image shows a smooth surface with planar morphology. Further, the quality of the epilayer film was investigated by AFM. AFM image of the InGaN epilayer has been shown in Figure 1e. The root mean square roughness of the $\mathrm{InGaN}$ epilayer was found to be $3.20 \mathrm{~nm}$.

The room-temperature photoluminescence spectrum of the epilayer film is shown in Figure 2a. The near-band edge emission peak of $\mathrm{n}^{+}$-InGaN epilayer was observed at $431 \mathrm{~nm}$, corresponding to a band gap of $2.88 \mathrm{eV}$. Vegard's law has been used to calculate the In composition $(x)$ in the ternary InGaN alloy for the device. There exists a deviation from Vegard's law that is referred to as the bowing parameter. This deviation arises due to the inhomogeneity in the indium incorporation. An equation that describes the band gap of InGaN alloy is given as follows 

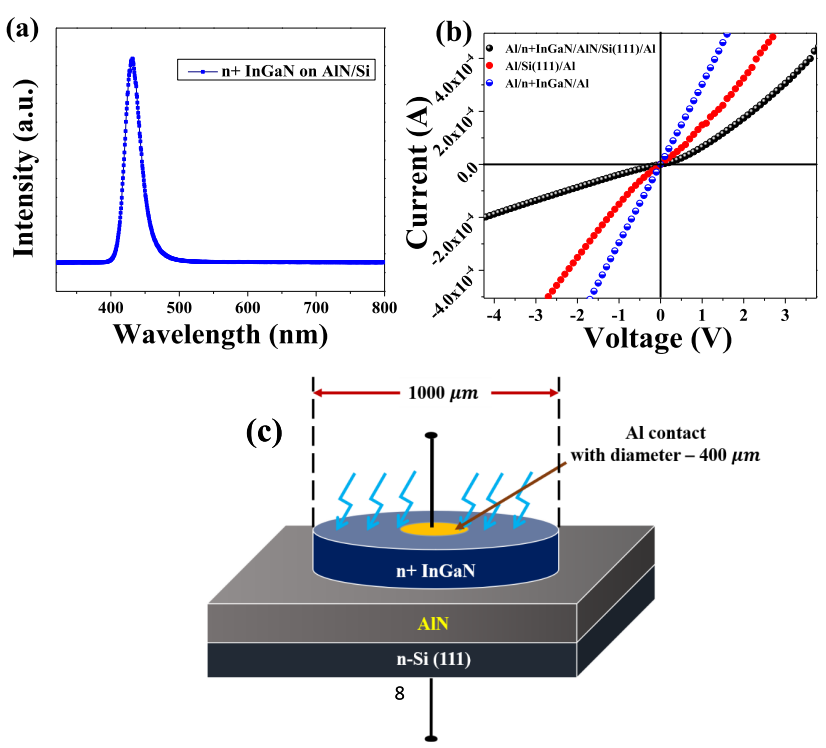

Figure 2. (a) Room-temperature photoluminescence spectrum of InGaN epilayer. (b) $I-V$ characteristics of the $\mathrm{n}^{+}-\mathrm{InGaN} / \mathrm{AlN} / \mathrm{n}$ $\mathrm{Si}(111)$ device at room temperature. (c) Schematic diagram of the device.

$$
\begin{aligned}
E_{g}\left(\operatorname{In}_{x} G a_{1-x} N\right)= & (1-x) E_{g}(G a N)+x E_{g}(\operatorname{InN}) \\
& -b x(1-x)
\end{aligned}
$$

where $E_{\mathrm{g}}(\mathrm{GaN})=3.41 \mathrm{eV},{ }^{41} E_{\mathrm{g}}(\operatorname{InN})=0.7 \mathrm{eV},{ }^{42}$ and bowing parameter $b=2.5 \mathrm{eV}^{43,44}$

Using eq 1 , the value of $x$ is estimated to be 0.104 (i.e., $10.4 \%$ ).

Room-temperature $I-V$ characteristics of the device $\left(\mathrm{Al} / \mathrm{n}^{+}\right.$$\mathrm{InGaN} / \mathrm{AlN} / \mathrm{n}-\mathrm{Si}(111) / \mathrm{Al}$ ) have been shown in Figure $2 \mathrm{~b}$. The device shows a rectifying behavior at room temperature similar to that of semiconductor-insulator-semiconductor (SIS) junction behavior reported in the literature for other materials. ${ }^{6,10,39,45,46}$ The linear nature of the $\mathrm{Al} / \mathrm{n}^{+}-\mathrm{InGaN} / \mathrm{Al}$ and $\mathrm{Al} / \mathrm{n}-\mathrm{Si}(111) / \mathrm{Al}$ in Figure $2 \mathrm{~b}$ illustrates that the contacts are Ohmic. The schematic diagram of the device has been depicted in Figure 2c, which shows an effective device area of $0.659 \mathrm{~mm}^{2}$ (Figure S1).

The carrier transport mechanisms for the detector under forward, reverse, and zero biases are described in Figure 3. The band gaps of $\mathrm{n}^{+}-\mathrm{InGaN}, \mathrm{AlN}$, and $\mathrm{n}-\mathrm{Si}(111)$ were taken as 2.88, $6.27 \mathrm{eV}$ (Figure S7), and $1.11 \mathrm{eV}$ (Figure S6), respectively. Room-temperature Hall measurements were carried out to know the carrier concentration of $\mathrm{InGaN}$ epilayer. The carrier concentration of the epilayer $N_{\mathrm{d}}$ was found to be $\sim 1.06 \times 10^{19}$ $\mathrm{cm}^{-3}$ ( $\mathrm{n}^{+}$type). Thus, it can be concluded that the $\mathrm{n}^{+}-\mathrm{InGaN}$ layer has been formed with $\mathrm{Si}$ doping. It has been estimated by theoretical calculations ${ }^{9,47}$ based on density functional theory (TCAD Silvaco) that the number of states in the conduction band $\left(N_{\mathrm{c}}\right)$ of the $\mathrm{n}^{+}-\mathrm{InGaN}$ layer is $2.15 \times 10^{18} \mathrm{~cm}^{-3}$. Substituting the values of $N_{\mathrm{c}}$ and carrier concentrations $N_{\mathrm{d}}$, the value of $\left(E_{\mathrm{c}}-E_{\mathrm{f}}\right)$ at room temperature $(300 \mathrm{~K})$ was obtained from eq 2 .

$$
E_{c}-E_{f}=K_{B} T \ln \left(\frac{N_{c}}{N_{d}}\right)
$$

where $K_{\mathrm{B}}$ is the Boltzmann constant, $T$ is the temperature, $E_{\mathrm{c}}$ is the conduction band minima, and $E_{\mathrm{f}}$ is the Fermi level. From eq $2, E_{\mathrm{c}}-E_{\mathrm{f}}$ is estimated to be $-0.041 \mathrm{eV}$ for $\mathrm{n}^{+}-\mathrm{InGaN}$ layer. The

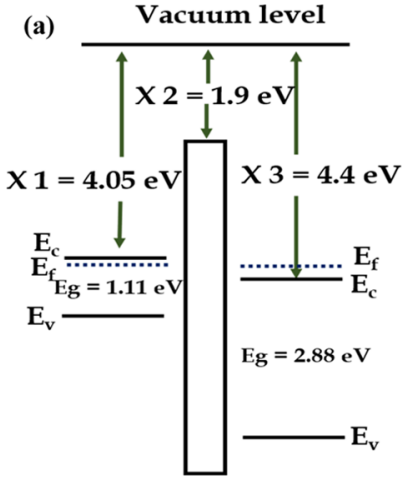

$\begin{array}{lll}\text { (b) } & \text { AlN } & \\ \text { n Si } & & \text { n+ InGaN }\end{array}$

(c)
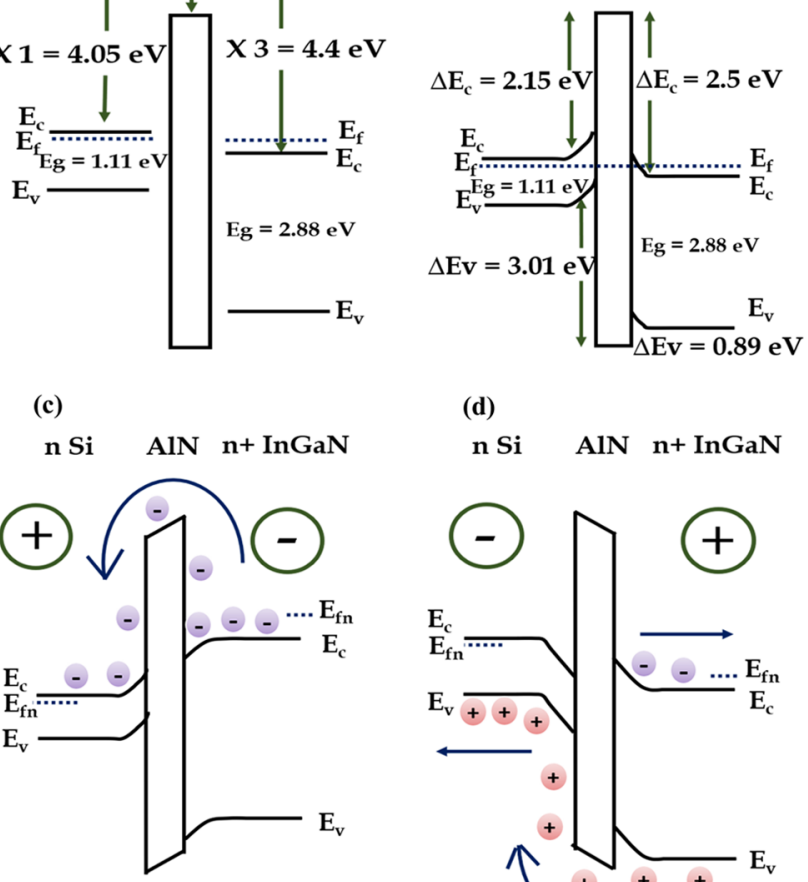

(d)

n Si AlN n+ InGaN

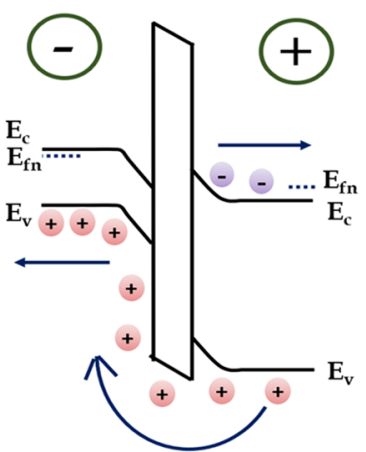

Figure 3. Energy band diagrams of $\mathrm{n}^{+}-\mathrm{InGaN} / \mathrm{AlN} / \mathrm{n}-\mathrm{Si}(111) \mathrm{S}-\mathrm{I}-\mathrm{S}$ heterojunction photodetector (a) before junction formation, (b) after junction formation (at thermal equilibrium), (c) under forward bias, and (d) under reverse bias.

negative value of $E_{\mathrm{c}}-E_{\mathrm{f}}$ suggests that the Fermi level $E_{\mathrm{f}}$ of $\mathrm{n}^{+}$InGaN layer would lie above the conduction band minima $E_{\mathrm{c}}$ of the corresponding layer, as shown in Figure 3a. Electron affinity of $\mathrm{n}^{+}-\mathrm{InGaN}$ was found to be $4.4 \mathrm{eV}$ as per theoretical calculations. ${ }^{40}$ The electron affinity of $\mathrm{n}-\mathrm{Si}(111)$ is taken as 4.05 $\mathrm{eV}^{34}$ and for AlN, it is taken as $1.9 \mathrm{eV}$.

The $\mathrm{n}^{+}$-InGaN epilayer was intentionally doped with $\mathrm{Si}$, which shows $\mathrm{n}^{+}$-type conductivity and the Fermi level lies in the conduction band at equilibrium condition, as shown in Figure 3b. For $\mathrm{n}^{+}-\mathrm{InGaN} / \mathrm{AlN} / \mathrm{n}-\mathrm{Si}(111)$ heterojunction at forward bias, the band of Si near AlN/n-Si(111) interface bends upward, as shown in Figure 3c, i.e., the Fermi level goes down for Si and up for $\mathrm{n}^{+}-\mathrm{InGaN}$, respectively.

At forward bias, the carriers are accumulated near the junction between the semiconductors $\left(\mathrm{n}^{+}-\mathrm{InGaN}\right)$ and insulator (AlN). The flow of current is dominated by one type of carriers (electrons) in forward bias condition. The accumulated carriers rapidly flow above the threshold voltage with a large number of carriers above the insulating layer. On the other hand, the flow of current is dominated by holes under reverse bias condition, as shown in Figure 3d. Under illumination with light $(\sim 580 \mathrm{~nm})$, photocurrent is observed in the region of zero bias with a power density of $0.1 \mathrm{~mW} / \mathrm{cm}^{2}$. An abrupt increase in the photocurrent has been observed at zero bias than that in either reverse or forward biases and is shown in Figure 4a.

We have also investigated the photodetection behavior with an asymmetric electrode configuration. We have used a fourstack metal electrode consisting of $\mathrm{Ti}(10 \mathrm{~nm}) / \mathrm{Al}(20 \mathrm{~nm}) / \mathrm{Ni}$ $(50 \mathrm{~nm}) / \mathrm{Au}(150 \mathrm{~nm})$ on $\mathrm{n}^{+}-\mathrm{InGaN}$, and an Al-metal electrode 

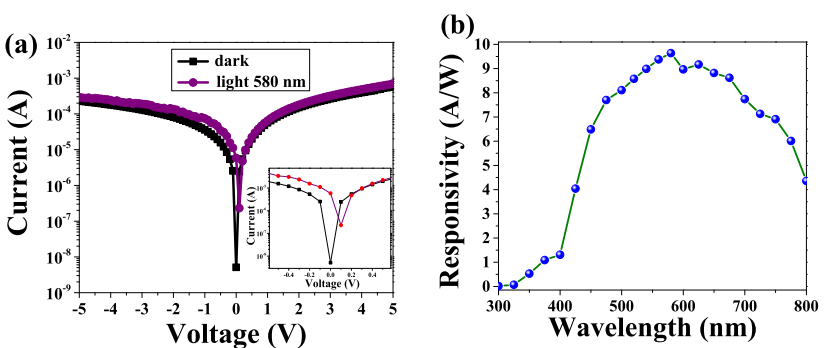

Figure 4. (a) Current-voltage $(I-V)$ characteristic of the $\mathrm{n}^{+}-\mathrm{InGaN} /$ $\mathrm{AlN} / \mathrm{n}-\mathrm{Si}(111)$ detector under dark and light $(580 \mathrm{~nm})$. The inset graph represents the zoomed view of current-voltage characteristics of the self-powered photodetector at zero bias. (b) Spectral response of the photodetector measured at zero bias.

on $\mathrm{Si}$ to obtain an asymmetrical electrode configuration, as shown in Figures S2-S5. It can be seen that the photocurrent generated with an asymmetrical configuration is lower than that with a symmetrical metal electrode although the nature of spectral response is same in both cases. The low photocurrent in an asymmetrical electrode could be due to high dark current density, which is limited by the contact electrode. The detectivity $\left(D^{*}\right)$ that depends on the dark current density is also low in an asymmetrical configuration.

Spectral response studies were carried out for the detector at zero bias $(\lambda=300-800 \mathrm{~nm})$. During spectral response measurements, light intensity was kept constant at $0.1 \mathrm{~mW} /$ $\mathrm{cm}^{2}$. Spectral response of the device has been shown in Figure $4 \mathrm{~b}$, and it can be seen that the device shows a broad band photodetection with a maximum response at $580 \mathrm{~nm}$.

After having maximum response at $580 \mathrm{~nm}, I-V$ characteristics were investigated by irradiating light of different wavelengths with a fixed intensity of $0.1 \mathrm{~mW} / \mathrm{cm}^{2}$ (Figure $5 \mathrm{a}$ ). The SIS photodetector exhibits photovoltaic properties with an open circuit voltage $V_{\mathrm{OC}}=0.112 \mathrm{~V}$ and a short circuit current $I_{\mathrm{SC}}$ $=888.6 \mu \mathrm{A} / \mathrm{cm}^{2}$ at $580 \mathrm{~nm}$ and is in accordance with other reported results. ${ }^{40} I-V$ characteristics of the device under
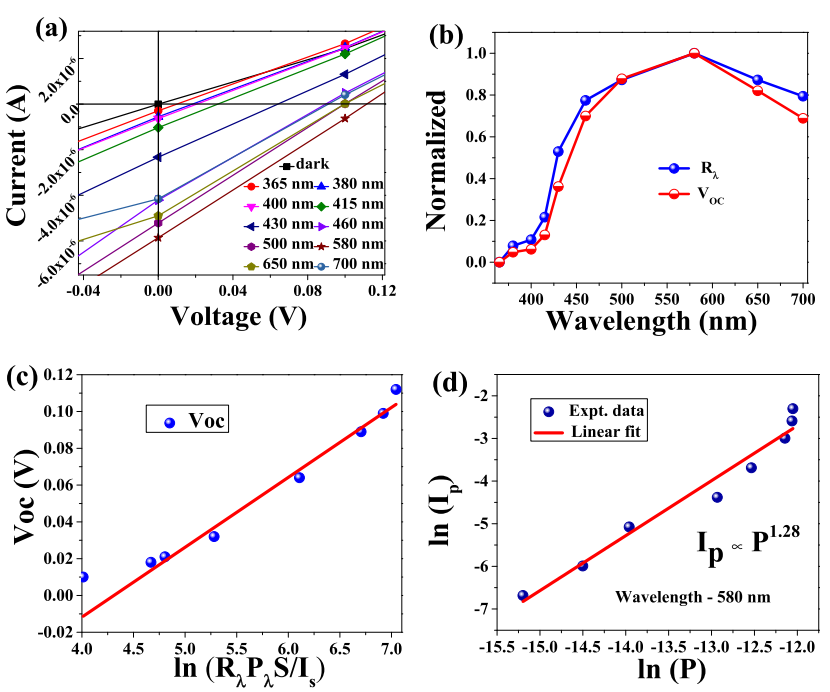

Figure 5. (a) $I-V$ characteristics of the $\mathrm{n}^{+}-\mathrm{InGaN} / \mathrm{AlN} / \mathrm{n}-\mathrm{Si}(111)$ detector under the dark and with illumination of light at different wavelengths. (b) Open circuit voltage $\left(V_{\mathrm{OC}}\right)$ of the self-powered photodetector as a function of wavelength. (c) Variation of $V_{\mathrm{OC}}$ with photoresponsivity. (d) Variation of photocurrent with light power density. illumination of different wavelengths have been presented in Figure 5a, keeping the light intensity constant at $0.1 \mathrm{~mW} / \mathrm{cm}^{2}$. Figure $5 \mathrm{~b}$ represents the variation of $V_{\mathrm{OC}}$ with different light wavelengths, and the maximum $V_{\mathrm{OC}}$ is observed at $580 \mathrm{~nm}$, which is in good agreement with our spectral response results. Further, the variation of $V_{\mathrm{OC}}$ with photoresponsivity has been presented in Figure $5 \mathrm{c}$ and is found to be varying linearly according to the following relation $3^{48}$

$$
V_{O C}=\frac{K_{B} T}{q} \ln \left(\frac{I_{\lambda}}{I_{S}}\right)
$$

with

$$
I_{\lambda}=R_{\lambda} P_{\lambda} S
$$

where $I_{\lambda}$ and $I_{S}$ are the reverse saturation current and photocurrent, respectively; $K_{\mathrm{B}}$ is the Boltzmann constant; $q$ is the electron charge; $R_{\lambda}$ is the photoresponsivity; $S$ is the illuminated junction area of the detector, which is $0.659 \mathrm{~mm}^{2}$; and $P_{\lambda}$ is the incident power of the light source of wavelength $\lambda$, which is $0.1 \mathrm{~mW} / \mathrm{cm}^{2}$. We have also examined the dependency of photocurrent on incident power, and the results are presented in Figure $5 \mathrm{~d}$. The relation between the photocurrent and illumination power density can be described by $I_{\mathrm{ph}} \propto P_{\lambda}^{\theta}$, where $\theta$ is the response between photocurrent and illumination power density. ${ }^{49}$ The fitted value of $\theta$ is found to be 1.28 . The nonunity value of $\theta$ explains the complex processes of photogenerated carriers through trapping, recombination, etc. ${ }^{50-53}$

The temporal response of the device is measured at zero bias as there is an abrupt increase in the photocurrent as compared to that in reverse or forward bias and the response at $580 \mathrm{~nm}$ is presented in Figure 6a. The response and recovery times of the device are found to be around $100 \mathrm{~ms}$, as shown in Figure $6 \mathrm{~b}, \mathrm{c}$, respectively. It can be noted that the time interval between two sampling points is around $100 \mathrm{~ms}$, which is due to instrumental limitation. To estimate the transit time constants precisely, we have used a high-speed setup, as depicted in Figure $6 \mathrm{~d}$. The setup consists of a mechanical optical chopper, which is used to generate optical pulses from the continuous wave lasers. A direct current voltage source is used to drive the device, and a digital storage oscilloscope is connected with a $1 \mathrm{M} \Omega$ impedance to measure the output. Figure 6e represents the transient response. To find out the response and recovery times, one responserecovery cycle is fitted with first-order exponential equations. ${ }^{54}$ The response and recovery times are found to be 19.9 and 21.4 $\mu$ s, respectively, as shown in Figure $6 \mathrm{f}$. It may be noted that the response and recovery times of the present detector are better than those for the previously reported InGaN-based photodetector. ${ }^{34}$ Detectivity $\left(D^{*}\right)^{55}$ is used to check the performance of the photodetector. It is defined by $D^{*}=\frac{R_{\lambda}}{\left(2 e J_{\mathrm{d}}\right)^{1 / 2}}$, where $R_{\lambda}$ is the responsivity, $J_{\mathrm{d}}$ is the dark current density of the detector, and $e$ is the electronic charge $\left(1.6 \times 10^{-19} \mathrm{C}\right)$. Detectivity is found to be $1.93 \times 10^{13} \mathrm{~cm} \mathrm{~Hz}^{1 / 2} \mathrm{~W}^{-1}$ at zero bias. The measured value of the detectivity is comparable to that of $\mathrm{GaN}$, $\mathrm{ZnO}$, and PPA-TiN-based photodevices. ${ }^{7,55-57}$ The responsivity and photogain $(G)$ of the detector were estimated from $R_{\lambda}=\frac{I_{\lambda}}{P_{\lambda} S}$ and $G=\frac{h c R_{\lambda}}{e \lambda}, 55$ respectively. The responsivity and $G$ were found to be $9.64 \mathrm{~A} / \mathrm{W}$ and 20.64 (at $580 \mathrm{~nm}$ ), respectively, which are better than previously reported values in the literature. ${ }^{20,34}$ 

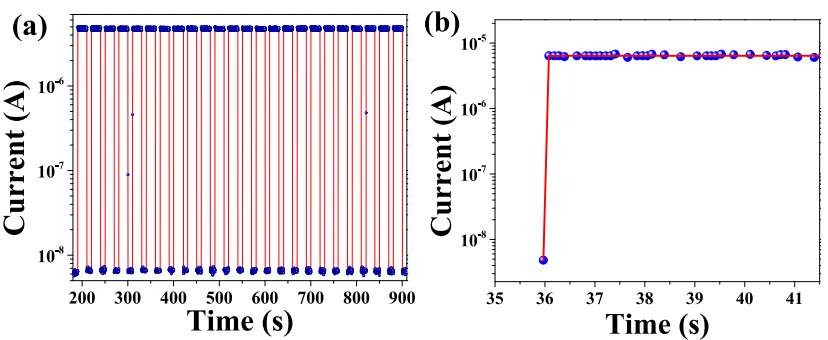

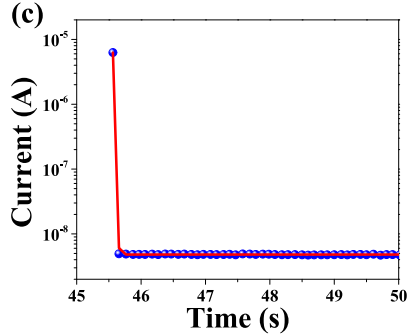

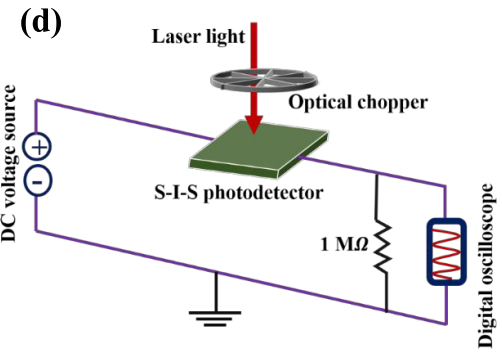

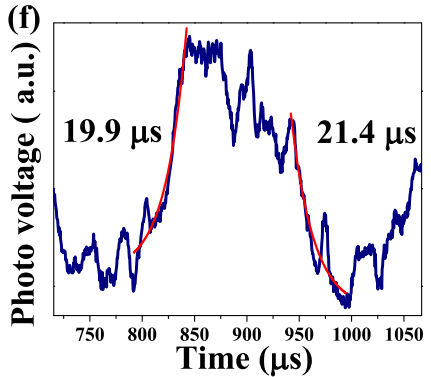

(e)

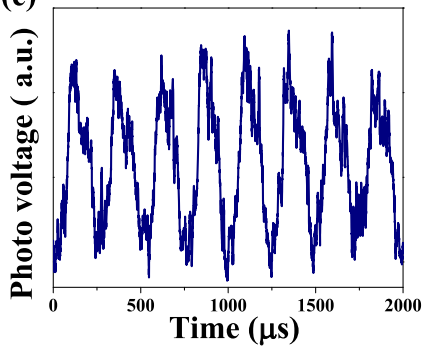

Figure 6. (a) Temporal response of the photodetector at zero bias with wavelength of light $580 \mathrm{~nm}$. (b, c) Single-cycle ON-OFF switching representing the response speed under light illumination at zero bias. (d) Schematic of a high-speed measurement setup. (e) Transient response measured with an optical chopper. (f) Exponential equation is fitted to find the ultrafast response and recovery times. (g) Intermediate energy levelassisted photoresponse at zero bias.

Table 1. Comparison of Characteristic Parameters of the Present $\mathbf{n}^{+}$-InGaN/AlN/n-Si(111) S-I-S Heterojunction Photodetector to Those of Other Self-Powered Photodetectors

\begin{tabular}{|c|c|c|c|c|c|c|c|}
\hline $\mathrm{PD}^{a}$ & type & $V_{\mathrm{oc}}(\mathrm{V})^{b}$ & $D^{*}\left(\mathrm{~cm} \mathrm{~Hz} \mathrm{~W}^{-1}\right)^{c}$ & $R_{\lambda}(\mathrm{A} / \mathrm{W})^{d}$ & $\tau_{\mathrm{g}}(\mathrm{ms})^{e}$ & $\tau_{\mathrm{d}}(\mathrm{ms})^{f}$ & refs \\
\hline $\mathrm{CuO} / \mathrm{Si}$ & $\mathrm{p}-\mathrm{n}$ & 0.16 & $3 \times 10^{9}$ & $3 \times 10^{-4}$ & 0.06 & 0.08 & 58 \\
\hline $\mathrm{ZnIn}_{2} \mathrm{~S}_{4} /$ agarose gel & hybrid & 0.63 & & $1.65 \times 10^{-2}$ & 25 & 120 & 59 \\
\hline $\mathrm{MoS}_{2}$ & transistor & 0.48 & & 107 & 260 & 267 & 60 \\
\hline graphene $/ \mathrm{MoS}_{2}$ & transistor & 0.012 & $\sim 10^{13}$ & 0.6 & 0.13 & 0.13 & 61 \\
\hline $\mathrm{MoS}_{2} / \mathrm{Si}$ & heterojunction & 0.21 & $\sim 10^{13}$ & 0.3 & 0.003 & 0.04 & 5 \\
\hline $\mathrm{ZnO} /$ Spiro-MeOTAD & hybrid & 0.1 & & 0.017 & 0.2 & 0.95 & 2 \\
\hline $\mathrm{ZnO} \mathrm{NR}$ & MIS & & $7.99 \times 10^{7}$ & $1.78 \times 10^{-6}$ & 100 & 100 & 62 \\
\hline $\mathrm{CH}_{3} \mathrm{NH}_{3} \mathrm{PbI}_{3}$ & hybrid & & $3.29 \times 10^{12}$ & 0.284 & 0.02 & 0.017 & 63 \\
\hline $\mathrm{PPA} / \mathrm{TiN}$ & hybrid & 0.78 & $1.92 \times 10^{11}$ & 0.57 & 9.23 & 18.12 & 7 \\
\hline $\mathrm{ZnO}$ homojunction nanofibers & $\mathrm{p}-\mathrm{n}$ & 0.55 & & & 3900 & 4700 & 64 \\
\hline $\mathrm{NiO} / \mathrm{TiO}_{2} \mathrm{NR}_{\mathrm{S}} / \mathrm{TiO}_{x}$ & heterojunction & & $2.50 \times 10^{12}$ & $5.66 \times 10^{-3}$ & less than 100 & less than 100 & 65 \\
\hline GaN MWA/Si & heterojunction & & $3.4 \times 10^{12}$ & $131 \times 10^{-3}$ & 2 & 2 & 66 \\
\hline $\mathrm{n}-\mathrm{InGaN} / \mathrm{n}-\mathrm{Si}$ & $\mathrm{n}-\mathrm{n}$ heterojunction & & & 0.0942 & 20 & 33 & 34 \\
\hline $\mathrm{n}^{+}-\mathrm{InGaN} / \mathrm{AlN} / \mathrm{n}-\mathrm{Si}$ & $\mathrm{S}-\mathrm{I}-\mathrm{S}$ heterojunction & 0.112 & $1.93 \times 10^{13}$ & 9.64 & 0.0199 & 0.0214 & present $\mathrm{w}$ \\
\hline
\end{tabular}

${ }^{a}$ Photodetector. ${ }^{b}$ Open circuit voltage. ${ }^{c}$ Detectivity. ${ }^{d}$ Responsivity. ${ }^{e}$ Rise time. ${ }^{f}$ Recovery time.

The photoresponsivity and other parameters of the detector are compared to those of other self-powered detectors in Table 1.
From the above spectral response studies, it can be seen that maximum responsivity is realized for $580 \mathrm{~nm}(2.13 \mathrm{eV})$. However, the band gap of the device is $2.88 \mathrm{eV}(431 \mathrm{~nm})$, as 
determined from the photoluminescence measurements (Figure 2). The variation of photocurrent with wavelength of $\mathrm{Al}$ / $\mathrm{InGaN} / \mathrm{Al}$ device is highest for $580 \mathrm{~nm}$ excitation (Figure S8) that ensures the presence of the intermediate energy level $\left(E_{\mathrm{i}}\right)$ at $\mathrm{n}^{+}-\mathrm{InGaN}$ layer, as depicted in Figure 6g. In this context, it may be noted that nitrogen vacancies in III-nitrides form an intermediate deep donor level and we believe that the photocurrent is highest due to the intermediate level, which is $2.13 \mathrm{eV}$ below the conduction band. ${ }^{67-70}$

Due to band bending at $\mathrm{n}^{+}-\mathrm{InGaN} / \mathrm{AlN}$ interface, an internal electric field is generated, which leads to the photoresponse at zero bias. At the lower wavelength side $\left\{h v>E_{\mathrm{g}}(2.88 \mathrm{eV})\right\}$, electrons are excited from the valence band to conduction band, leaving behind holes in the valence band. Due to the presence of an internal electric field, the holes left behind in the valence band and the electrons in the conduction band are drifted and collected, giving rise to a photocurrent. At higher wavelengths $\left\{h v \leq E_{\mathrm{g}}(2.88 \mathrm{eV})\right\}$, the electrons get excited from the intermediate energy level (at $580 \mathrm{~nm}$ ) to the conduction band, leaving behind immobile charges at the intermediate level, as depicted in Figure 6g. This intermediate energy level repels the holes, preventing recombination and thus increasing the conductivity under illumination. As one moves toward even higher wavelengths $(h v \leq 2.13 \mathrm{eV})$, the absorption of photons is reduced due to the absence of suitable intermediate energy levels in the band gap $\left(E_{\mathrm{g}}\right)$, thereby leading to a dip in the responsivity, as shown in Figure 4. Therefore, we suggest that the intermediate energy level, arising due to the nitrogen vacancies in InGaN lattice, is playing a dominant role in the responsivity.

\section{CONCLUSIONS}

$\mathrm{n}^{+}$-InGaN epilayer was grown by PAMBE on AlN template on the $\mathrm{n}-\mathrm{Si}(111)$ substrate. We have shown self-powered, ultrafast photoresponse and broad band photodetection capabilities of the $\mathrm{n}^{+}$-InGaN-based detector due to better crystalline and optical quality. The self-powered photodetector exhibited high spectral responsivity (9.64 A/W), detectivity, and high response speed for low-intensity irradiance $\left(0.1 \mathrm{~mW} / \mathrm{cm}^{2}\right)$, which demonstrates, to the best of our knowledge, one of the best results in terms of device performances till date. This work opens up a technical route for SIS heterojunction photodetectors to be used as promising devices for nanoscale electronics, optoelectronics, integrated circuits, and light wave communications.

\section{ASSOCIATED CONTENT}

\section{S Supporting Information}

The Supporting Information is available free of charge on the ACS Publications website at DOI: 10.1021/acsami.8b22569.

Device processing, band gap measurement of Si and AlN, comparison between the symmetrical and asymmetrical electrode, and variation of photocurrent with wavelength on InGaN (PDF)

\section{AUTHOR INFORMATION}

\section{Corresponding Authors}

*E-mail: nanda@iisc.ac.in (K.K.N.).

*E-mail: sbk@iisc.ac.in (S.B.K.).

\section{ORCID $\odot$}

Rohit Pant: 0000-0002-4591-5752

K. K. Nanda: 0000-0001-9496-1408

S. B. Krupanidhi: 0000-0001-6393-0908

\section{Notes}

The authors declare no competing financial interest.

\section{ACKNOWLEDGMENTS}

A.M.C. acknowledges Dr. Kausik Majumdar and Dr. Sangeeth Kallat of the ECE department of IISc Bangalore for their assistance in high-speed measurements. Akash Singh is acknowledged for his useful comments on this paper.

\section{REFERENCES}

(1) Jin, W.; Ye, Y.; Gan, L.; Yu, B.; Wu, P.; Dai, Y.; Meng, H.; Guo, X.; Dai, L. Self-Powered High Performance Photodetectors Based on CdSe Nanobelt/Graphene Schottky Junctions. J. Mater. Chem. 2012, 22, 2863-2867.

(2) Game, O.; Singh, U.; Kumari, T.; Banpurkar, A.; Ogale, S. $\mathrm{ZnO}(\mathrm{N})$-Spiro-MeOTAD Hybrid Photodiode: An Efficient SelfPowered Fast-Response UV (Visible) Photosensor. Nanoscale 2014, 6, 503-513.

(3) Li, X.; Gao, C.; Duan, H.; Lu, B.; Wang, Y.; Chen, L.; Zhang, Z.; Pan, X.; Xie, E. High-Performance Photoelectrochemical-Type SelfPowered UV Photodetector Using Epitaxial $\mathrm{TiO} 2 / \mathrm{SnO} 2$ Branched Heterojunction Nanostructure. Small 2013, 9, 2005-2011.

(4) Konstantatos, G.; Sargent, E. H. Nanostructured Materials for Photon Detection. Nat. Nanotechnol. 2010, 5, 391-400.

(5) Wang, L.; Jie, J.; Shao, Z.; Zhang, Q.; Zhang, X.; Wang, Y.; Sun, Z.; Lee, S. T. $\mathrm{MoS}_{2} / \mathrm{Si}$ Heterojunction with Vertically Standing Layered Structure for Ultrafast, High-Detectivity, Self-Driven Visible-near Infrared Photodetectors. Adv. Funct. Mater. 2015, 25, 2910-2919.

(6) Ashok, S.; Fonash, S. J.; Sharma, P. P. Spray-Deposited ITOSilicon SIS Heterojunction Solar Cells. IEEE Trans. Electron Devices 1980, 27, 725-730.

(7) Hussain, A. A.; Sharma, B.; Barman, T.; Pal, A. R. Self-Powered Broadband Photodetector Using Plasmonic Titanium Nitride. ACS Appl. Mater. Interfaces 2016, 8, 4258-4265.

(8) Mahala, P.; Behura, S. K.; Ray, A.; Dhanavantri, C.; Jani, O. P$\mathrm{GaN} / \mathrm{i}-\mathrm{In}_{\mathrm{x}} \mathrm{xGa}{ }_{\mathrm{x}} \mathrm{xN} / \mathrm{n}-\mathrm{GaN}$ Solar Cell with Indium Compositional Grading. Opt. Quantum Electron. 2015, 47, 1117-1126.

(9) Brown, G. F.; Ager, J. W.; Walukiewicz, W.; Wu, J. Finite Element Simulations of Compositionally Graded InGaN Solar Cells. Sol. Energy Mater. Sol. Cells 2010, 94, 478-483.

(10) Shewchun, J.; Dubow, J.; Wilmsen, C. W.; Singh, R.; Burk, D.; Wager, J. F. The Operation of the Semiconductor-Insulator-Semiconductor Solar Cell: Experiment. J. Appl. Phys. 1979, 50, 2832-2839.

(11) Nawaz, M.; Ahmad, A. A TCAD-Based Modeling of GaN/ InGaN/Si Solar Cells. Semicond. Sci. Technol. 2012, 27, No. 035019.

(12) Gour, K. S.; Bhattacharyya, B.; Singh, O. P.; Yadav, A. K.; Husale, S.; Singh, V. N. Nanostructured $\mathrm{Cu}_{2} \mathrm{ZnSnS}_{4}$ (CZTS) Thin Film for SelfPowered Broadband Photodetection. J. Alloys Compd. 2018, 735, 285290.

(13) Teng, F.; Hu, K.; Ouyang, W.; Fang, X. Photoelectric Detectors Based on Inorganic P-Type Semiconductor Materials. Adv. Mater. 2018, 30, No. 1706262.

(14) Ouyang, W.; Teng, F.; Fang, X. High Performance BiOCl Nanosheets $/ \mathrm{TiO}_{2}$ Nanotube Arrays Heterojunction UV Photodetector: The Influences of Self-Induced Inner Electric Fields in the BiOCl Nanosheets. Adv. Funct. Mater. 2018, 28, No. 1707178.

(15) Yu, P.; Hu, K.; Chen, H.; Zheng, L.; Fang, X. Novel p-p Heterojunctions Self-Powered Broadband Photodetectors with Ultrafast Speed and High Responsivity. Adv. Funct. Mater. 2017, 27, No. 1703166.

(16) Peng, L.; Hu, L.; Fang, X. Energy Harvesting for Nanostructured Self-Powered Photodetectors. Adv. Funct. Mater. 2014, 24, 2591-2610.

(17) Zheng, L.; Hu, K.; Teng, F.; Fang, X. Novel UV-Visible Photodetector in Photovoltaic Mode with Fast Response and Ultrahigh Photosensitivity Employing $\mathrm{Se} / \mathrm{TiO}_{2}$ Nanotubes Heterojunction. Small 2017, 13, No. 1602448.

(18) Li, S.; Wang, S.; Liu, K.; Zhang, N.; Zhong, Z.; Long, H.; Fang, G. Self-Powered Blue-Sensitive Photodetector Based on PEDOT:PSS/ 
$\mathrm{SnO}_{2}$ microwires Organic/Inorganic $\mathrm{p}-\mathrm{n}$ Heterojunction. Appl. Phys. A: Mater. Sci. Process. 2015, 119, 1561-1566.

(19) Zhao, B.; Wang, F.; Chen, H.; Zheng, L.; Su, L.; Zhao, D.; Fang, X. An Ultrahigh Responsivity $\left(9.7 \mathrm{~mA} \mathrm{~W}^{-1}\right)$ Self-Powered Solar-Blind Photodetector Based on Individual $\mathrm{ZnO}-\mathrm{Ga}_{2} \mathrm{O}_{3}$ Heterostructures. Adv . Funct. Mater. 2017, 27, No. 1700264.

(20) Hatch, S. M.; Briscoe, J.; Dunn, S. A Self-Powered ZnONanorod/CuSCN UV Photodetector Exhibiting Rapid Response. Adv. Mater. 2013, 25, 867-871.

(21) Dharmarasu, N.; Yamaguchi, M.; Khan, A.; Yamada, T.; Tanabe, T.; Takagishi, S.; Takamoto, T.; Ohshima, T.; Itoh, H.; Imaizumi, M.; Matsuda, S. High-Radiation-Resistant InGaP, InGaAsP, and InGaAs Solar Cells for Multijuction Solar Cells. Appl. Phys. Lett. 2001, 79, 2399-2401.

(22) Fang, X.; Bando, Y.; Liao, M.; Zhai, T.; Gautam, U. K.; Li, A.; Koide, Y.; Golberg, D. An Efficient Way to Assemble ZnS Nanobelts as Ultraviolet-Light Sensors with Enhanced Photocurrent and Stability By. Adv. Funct. Mater. 2010, 20, 500-508.

(23) Kumar, M.; Roul, B.; Bhat, T. N.; Rajpalke, M. K.; Krupanidhi, S. B. Structural Characterization and Ultraviolet Photoresponse of GaN Nanodots Grown by Molecular Beam Epitaxy. Appl. Phys. Express 2012, 5, No. 085202.

(24) Kumar, M.; Roul, B.; Rajpalke, M. K.; Bhat, T. N.; Kalghatgi, A. T.; Krupanidhi, S. B. Electrical Transport Studies of MBE Grown InGaN/Si Isotype Heterojunctions. Curr. Appl. Phys. 2013, 13, 26-30.

(25) Neufeld, C. J.; Toledo, N. G.; Cruz, S. C.; Iza, M.; DenBaars, S. P.; Mishra, U. K. High Quantum Efficiency InGaN/GaN Solar Cells with $2.95 \mathrm{eV}$ Band Gap. Appl. Phys. Lett. 2008, 93, No. 143502.

(26) Jani, O.; Ferguson, I.; Honsberg, C.; Kurtz, S. Design and Characterization of GaN/InGaN Solar Cells. Appl. Phys. Lett. 2007, 91, No. 132117

(27) Jain, S. C.; Willander, M.; Narayan, J.; Van Overstraeten, R. IIINitrides: Growth, Characterization, and Properties. J. Appl. Phys. 2000, 87, 965-1006.

(28) Paul, S.; Helwig, A.; Müller, G.; Furtmayr, F.; Teubert, J.; Eickhoff, M. Opto-Chemical Sensor System for the Detection of H2and Hydrocarbons Based on InGaN/GaN Nanowires. Sens. Actuators, B 2012, 173, 120-126.

(29) Ho, C. H.; Lin, G. J.; Fu, P. H.; Lin, C. A.; Yang, P. C.; Chan, I. M.; Lai, K. Y.; He, J. H. An Efficient Light-Harvesting Scheme Using $\mathrm{SiO}_{2}$ Nanorods for InGaN Multiple Quantum Well Solar Cells. Sol. Energy Mater. Sol. Cells 2012, 103, 194-198.

(30) Pau, J. L.; Anduaga, J.; Rivera, C.; Navarro, A.; Alava, I.; Redondo, M.; Muñoz, E. Optical Sensors Based on III-Nitride Photodetectors for Flame Sensing and Combustion Monitoring. Appl. Opt. 2006, 45, 7498-7503.

(31) Sekimoto, T.; Shinagawa, S.; Uetake, Y.; Noda, K.; Deguchi, M.; Yotsuhashi, S.; Ohkawa, K. Tandem Photo-Electrode of InGaN with Two Si p-n Junctions for $\mathrm{CO}_{2}$ Conversion to $\mathrm{HCOOH}$ with the Efficiency Greater than Biological Photosynthesis. Appl. Phys. Lett. 2015, 106, No. 073902.

(32) Li, K. H.; Fu, W. Y.; Cheung, Y. F.; Wong, K. K. Y.; Wang, Y.; Lau, K. M.; Choi, H. W. Monolithically Integrated InGaN/GaN LightEmitting Diodes, Photodetectors, and Waveguides on Si Substrate. Optica 2018, 5, 564-569.

(33) Ho, K.-T.; Chen, R.; Liu, G.; Shen, C.; Holguin-Lerma, J.; AlSaggaf, A. A.; Ng, T. K.; Alouini, M.-S.; He, J.-H.; Ooi, B. S. 32 Gigabitper-Second Visible Light Communication Link with InGaN/GaN MQW Micro-Photodetector. Opt. Express 2018, 26, 3037-3045.

(34) Chandan, G.; Mukundan, S.; Mohan, L.; Roul, B.; Krupanidhi, S. B. Trap Modulated Photoresponse of InGaN/Si Isotype Heterojunction at Zero-Bias. J. Appl. Phys. 2015, 118, No. 024503.

(35) Tchernycheva, M.; Messanvi, A.; de Luna Bugallo, A.; Jacopin, G.; Lavenus, P.; Rigutti, L.; Zhang, H.; Halioua, Y.; Julien, F. H.; Eymery, J.; Durand, C. Integrated Photonic Platform Based on InGaN/ GaN Nanowire Emitters and Detectors. Nano Lett. 2014, 14, 35153520.

(36) Krtschil, A.; Kielburg, A.; Witte, H.; Krost, A.; Christen, J.; Wenzel, A.; Rauschenbach, B. Electrical Characterization of Deep
Defect States in Galliumnitride Co-Implanted with Magnesium and Sulfur Ions. Mater. Sci. Eng., B 2002, 93, 85-89.

(37) Tran, C. A.; Karlicek, R. F.; Schurman, M.; Osinsky, A.; Merai, V.; Li, Y.; Eliashevich, I.; Brown, M. G.; Nering, J.; Ferguson, I.; Stall, R. Phase Separation in InGaN/GaN Multiple Quantum Wells and Its Relation to Brightness of Blue and Green LEDs. J. Cryst. Growth 1998, 195, 397-400.

(38) Nath, D. N.; Gür, E.; Ringel, S. A.; Rajan, S. Molecular Beam Epitaxy of N-Polar InGaN. Appl. Phys. Lett. 2010, 97, No. 071903.

(39) Kumar, M.; Roul, B.; Bhat, T. N.; Rajpalke, M. K.; Kalghatgi, A. T.; Krupanidhi, S. B. Carrier-Transport Studies of III-Nitride $/ \mathrm{Si}_{3} \mathrm{~N}_{4} / \mathrm{Si}$ Isotype Heterojunctions. Phys. Status Solidi A 2012, 209, 994-997.

(40) Ager, J. W.; Reichertz, L. A.; Cui, Y.; Romanyuk, Y. E.; Kreier, D.; Leone, S. R.; Yu, K. M.; Schaff, W. J.; Walukiewicz, W. Electrical Properties of InGaN-Si Heterojunctions. Phys. Status Solidi C 2009, 6, S413-S416.

(41) Kumar, M.; Roul, B.; Bhat, T. N.; Rajpalke, M. K.; Misra, P.; Kukreja, L. M.; Sinha, N.; Kalghatgi, A. T.; Krupanidhi, S. B. Improved Growth of GaN Layers on Ultra Thin Silicon Nitride/Si ( $\left.\begin{array}{lll}1 & 1 & 1\end{array}\right)$ by RFMBE. Mater. Res. Bull. 2010, 45, 1581-1585.

(42) Wu, J.; Walukiewicz, W.; Yu, K. M.; Ager, J. W.; Haller, E. E.; Lu, H.; Schaff, W. J.; Saito, Y.; Nanishi, Y. Unusual Properties of the Fundamental Band Gap of InN. Appl. Phys. Lett. 2002, 80, 3967-3969.

(43) Romanyuk, Y. E.; Kreier, D.; Cui, Y.; Yu, K. M.; Ager, J. W.; Leone, S. R. Molecular Beam Epitaxy of InGaN Thin Films on Si(111): Effect of Substrate Nitridation. Thin Solid Films 2009, 517, 6512-6515.

(44) Kumar, M.; Roul, B.; Bhat, T. N.; Rajpalke, M. K.; Kalghatgi, A. T.; Krupanidhi, S. B. Band-Structure Lineup at $\operatorname{In}_{0.2} \mathrm{Ga}_{0.8} \mathrm{~N} / \mathrm{Si}$ Heterostructures by $\mathrm{x}$-Ray Photoelectron Spectroscopy. Jpn. J. Appl. Phys. 2012, 51, No. 020203.

(45) Shewchun, J.; Dubow, J.; Myszkowski, A.; Singh, R. The Operation of the Semiconductor-Insulator-Semiconductor (SIS) Solar Cell: Theory. J. Appl. Phys. 1978, 49, 855-864.

(46) Jeong, H.; Bang, S.; Oh, H. M.; Jeong, H. J.; An, S. J.; Han, G. H.; Kim, H.; Kim, K. K.; Park, J. C.; Lee, Y. H.; Lerondel, G.; Jeong, M. S. Semiconductor-Insulator-Semiconductor Diode Consisting of Monolayer MoS2, h-BN, and GaN Heterostructure. ACS Nano 2015, 9, 10032-10038.

(47) Elbar, M.; Alshehri, B.; Tobbeche, S.; Dogheche, E. Design and Simulation of InGaN/GaN p-i-n Photodiodes. Phys. Status Solidi A 2018, 215, No. 1700521.

(48) Bhattacharya, P. Semiconductor Optoelectronic Devices; Prentice Hall, 1997.

(49) Krishna, S.; Sharma, A.; Aggarwal, N.; Husale, S.; Gupta, G. Ultrafast Photoresponse and Enhanced Photoresponsivity of Indium Nitride Based Broad Band Photodetector. Sol. Energy Mater. Sol. Cells 2017, 172, 376-383.

(50) Rose, A. Concepts in Photoconductivity and Allied Topics, 1978.

(51) Silver, M.; Olness, D.; Swicord, M.; Jarnagin, R. C. Photogeneration of Free Carriers in Organic Crystals via Exciton-Exciton Interactions. Phys. Rev. Lett. 1963, 10, 12.

(52) Choi, S. I. L.; Rice, S. A. Exciton-Exciton Interactions and Photoconductivity in Crystalline Anthracene. J. Chem. Phys. 1963, 38, 366-373.

(53) Almeleh, N.; Harrison, S. E. Photoconductive Processes in Pure and Doped Triphenylene. J. Phys. Chem. Solids 1965, 26, 1571-1584.

(54) Mukhokosi, E. P.; Krupanidhi, S. B.; Nanda, K. K. An Extrinsic Approach Toward Achieving Fast Response and Self-Powered Photodetector. Phys. Status Solidi A 2018, 215, No. 1800470.

(55) Roul, B.; Pant, R.; Chirakkara, S.; Chandan, G.; Nanda, K. K.; Krupanidhi, S. B. Enhanced UV Photodetector Response Of. IEEE Trans. Electron Devices 2017, 64, 4161-4166.

(56) Peng, M.; Liu, Y.; Yu, A.; Zhang, Y.; Liu, C.; Liu, J.; Wu, W.; Zhang, K.; Shi, X.; Kou, J.; Zhai, J.; Wang, Z. L. Flexible Self-Powered Gan Ultraviolet Photoswitch with Piezo-Phototronic Effect Enhanced On/Off Ratio. ACS Nano 2016, 10, 1572-1579.

(57) Pant, R.; Shetty, A.; Chandan, G.; Roul, B.; Nanda, K. K.; Krupanidhi, S. B. In-Plane Anisotropic Photoconduction in Nonpolar 
Epitaxial a-Plane GaN. ACS Appl. Mater. Interfaces 2018, 10, 1691816923.

(58) Hong, Q.; Cao, Y.; Xu, J.; Lu, H.; He, J.; Sun, J. L. Self-Powered Ultrafast Broadband Photodetector Based on p-n Heterojunctions of $\mathrm{CuO} / \mathrm{Si}$ Nanowire Array. ACS Appl. Mater. Interfaces 2014, 6, 2088720894.

(59) Mandal, L.; Chaudhari, N. S.; Ogale, S. Self-Powered UV-Vis Photodetector Based on $\mathrm{ZnIn}_{2} \mathrm{~S}_{4} /$ Hydrogel Interface. ACS Appl. Mater. Interfaces 2013, 5, 9141-9147.

(60) Zhong, X.; Zhou, W.; Peng, Y.; Zhou, Y.; Zhou, F.; Yin, Y.; Tang, D. Multi-Layered $\mathrm{MoS}_{2}$ Phototransistors as High Performance Photovoltaic Cells and Self-Powered Photodetectors. RSC Adv. 2015, 5, 45239-45248.

(61) Li, X.; Wu, J.; Mao, N.; Zhang, J.; Lei, Z.; Liu, Z.; Xu, H. A SelfPowered Graphene- $\mathrm{MoS}_{2}$ Hybrid Phototransistor with Fast Response Rate and High on-off Ratio. Carbon 2015, 92, 126-132.

(62) Zhang, Z.; Liao, Q.; Yu, Y.; Wang, X.; Zhang, Y. Enhanced Photoresponse of $\mathrm{ZnO}$ Nanorods-Based Self-Powered Photodetector by Piezotronic Interface Engineering. Nano Energy 2014, 9, 237-244.

(63) Li, D.; Dong, G.; Li, W.; Wang, L. High Performance OrganicInorganic Perovskite-Optocoupler Based on Low-Voltage and Fast Response Perovskite Compound Photodetector. Sci. Rep. 2015, 5, No. 7902.

(64) Ning, Y.; Zhang, Z.; Teng, F.; Fang, X. Novel Transparent and Self-Powered UV Photodetector Based on Crossed $\mathrm{ZnO}$ Nanofiber Array Homojunction. Small 2018, 14, No. e1703754.

(65) Gao, Y.; Xu, J.; Shi, S.; Dong, H.; Cheng, Y.; Wei, C.; Zhang, X.; Yin, S.; Li, L. $\mathrm{TiO}_{2}$ Nanorod Arrays Based Self-Powered UV Photodetector: Heterojunction with $\mathrm{NiO}$ Nanoflakes and Enhanced UV Photoresponse. ACS Appl. Mater. Interfaces 2018, 10, 1126911279 .

(66) Song, W.; Wang, X.; Chen, H.; Guo, D.; Qi, M.; Wang, H.; Luo, X.; Luo, X.; Li, G.; Li, S. High-Performance Self-Powered UV-Vis-NIR Photodetectors Based on Horizontally Aligned GaN Microwire Array/ Si Heterojunctions. J. Mater. Chem. C 2017, 5, 11551-11558.

(67) Diallo, I. C.; Demchenko, D. O. Native Point Defects in GaN: A Hybrid-Functional Study. Phys. Rev. Appl. 2016, 6, No. 064002.

(68) Limpijumnong, S.; Van de Walle, C. G. Diffusivity of Native Defects in GaN. Phys. Rev. B 2004, 69, No. 035207.

(69) Janotti, A.; Lyons, J. L.; Van De Walle, C. G. Hybrid Functional Calculations of Native Point Defects in InN. Phys. Status Solidi A 2012, 209, 65-70.

(70) Reshchikov, M. A.; Demchenko, D. O.; McNamara, J. D.; Fernández-Garrido, S.; Calarco, R. Green Luminescence in Mg-Doped GaN. Phys. Rev. B 2014, 90, No. 035207. 